\title{
Responses by humans to oral chemical irritants as a function of locus of stimulation
}

\author{
HARRY T. LAWLESS \\ S. C. Johnson \& Son, Racine, Wisconsin \\ and \\ DAVID A. STEVENS \\ Clark University, Worcester, Massachusetts
}

\begin{abstract}
Different areas of the mouth varied in responsiveness to chemical irritation. Subjects were stimulated with 7-mm filter-paper disks containing capsaicin or piperine, which are irritant components of red and black pepper, in seven different regions of the mouth. They reported intense sensations from stimulation of the tip of the tongue, side of the tongue, and posterior palate, all of which contain gustatory receptors, and less intense sensations from the cheek and anterior palate. Capsaicin produced relatively more intense responses from the lip and posterior tongue than did piperine. Sensations produced by stimulation of these small areas grew over time. The patterns of qualitative adjectives used to describe the sensations arising from the two compounds were not the same. These results suggest that irritative chemical stimuli may be qualitatively differentiable.
\end{abstract}

A fundamental characteristic of sensory systems with spatially distributed arrays of receptors is variation in sensitivity to different stimuli across the spatial array. In the skin senses, for example, variations in sensitivity to thermal, pressure, vibrotactile, and pain stimuli have been "mapped" across the body surface (Geldard, 1972; Kenshalo, 1960; Kenshalo, Decker, \& Hamilton, 1967; Stevens, Marks, \& Simonson, 1974; Wilska, 1954). Spatial variation in responsiveness is also a characteristic of the mouth. Collings (1974) and Sandick and Cardello (1981) compared the responsiveness of oral areas to tastants, and Green (1984) studied spatial differences in oral responsiveness to thermal stimuli. However, little attention has been paid to the assessment of spatial variation in oral responsiveness to irritative compounds. Previous research is limited to two reports. In one the tongue was stimulated only at the tongue tip and root (DunerEngstrom, Fredholm, Larsson, Lundberg, \& Saria, 1986), and in the second, the whole mouth was stimulated without localization of stimuli (Lawless, 1984). One goal of the present study was to assess differences in oral responsiveness to irritants over more areas and with a higher degree of stimulus control than in previous studies.

The importance of understanding spatial variation lies not only in psychophysical documentation, but in the implications for anatomical and physiological correlates of such variation. Spatial variation in responsiveness must

The authors thank Robin Damrad and Debra Thomason for technical assistance. This study was supported by NIH Grant NS 20616. Address correspondence to David A. Stevens, Psychology Department, Clark University, Worcester, MA 01610. arise from differences in receptor type, receptor density, or aspects of the receptor environments, such as depth in the epithelium, that could influence the accessibility of stimuli to receptors.

Differences in spatial patterns of responsiveness across the parts of the mouth could also give rise to qualitative differentiation of irritative stimuli. An unresolved question is whether there are perceptually different qualities of irritation, or whether all types of irritation feel the same. To further address this possibility, we had subjects describe the sensory qualities elicited by localized stimulation in addition to judging perceived intensity.

\section{METHOD}

\section{Subjects}

Eight male and 12 female paid volunteers, 18-27 years of age, served as subjects. One male and 2 females were smokers. Before participating, all were informed of the general nature of the study and of their right to terminate their participation at any time.

\section{Stimuli}

Stimulation with wetted swatches of filter paper has been found to be a reliable technique for localizing tastants to particular parts of the oral epithelium (Collings, 1974). Stimuli were administered on 7-mm disks of Whatman Qualitative Grade 1 filter paper to which either $2.5 \mu \mathrm{g}$ capsaicin (Sigma Grade 1) or $230 \mu \mathrm{g}$ piperine (Sigma) in ethanol solutions had been added. These concentrations had been found in pilot work to produce equally intense sensations on the tip of the tongue. The ethanol evaporated from the paper prior to the application of the stimulus to the tongue.

\section{Procedure}

Subjects were instructed in magnitude estimation and were given practice in judging the weights of visually identical jars of 100 , 200,400 , and $800 \mathrm{~g}$, presented in random order three times each. 


\section{CAPSAICIN}

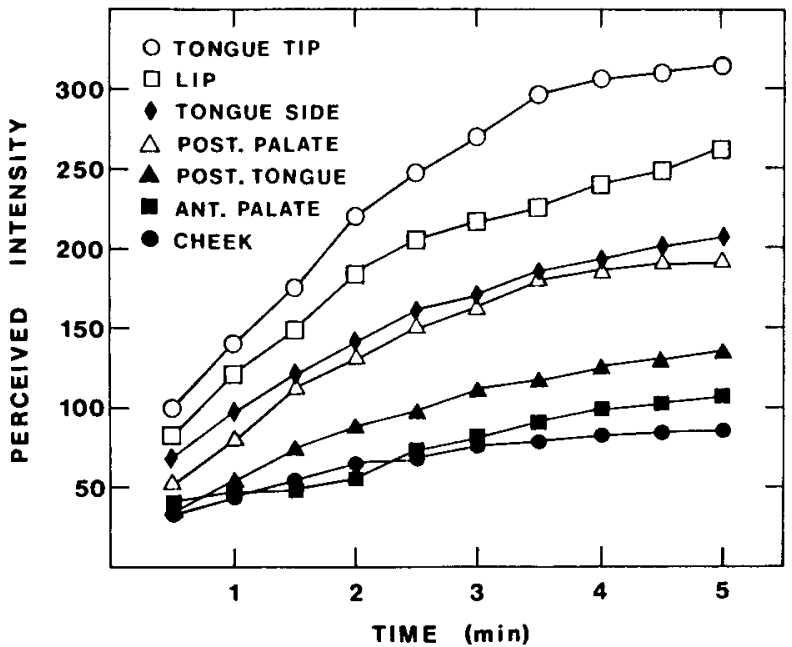

Figure 1. Mean perceived intensity of capsaicin stimuli for the seven loci in the mouth over time. The data were normalized such that the initial rating of the stimulus on the tip of the tongue was set equal to 100 .

\section{PIPERINE}

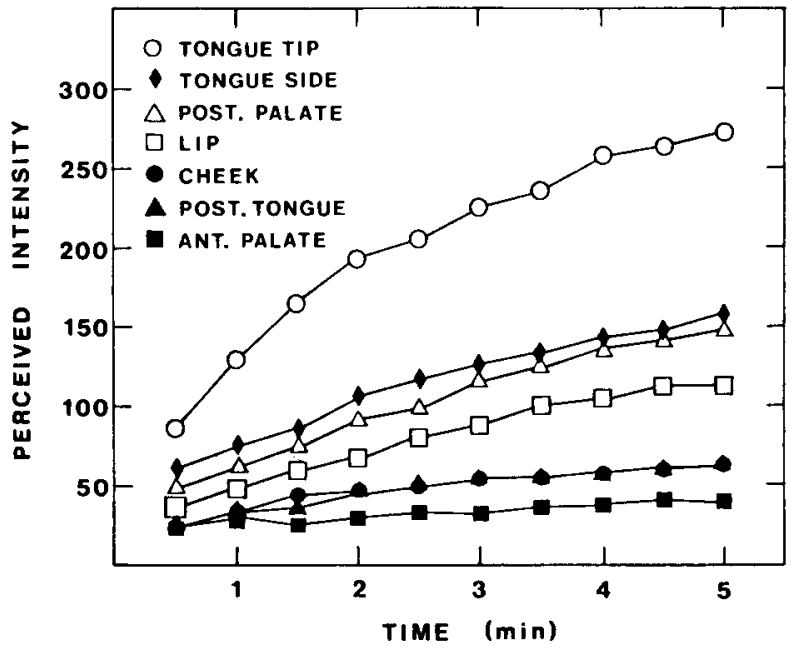

Figure 2. Mean perceived intensity of piperine stimuli for the seven loci in the mouth over time.

No standard was identified and no modulus was assigned either during practice or during the experiment proper.

Seven places in the mouth were independently stimulated with two irritants: (1) the midline dorsal surface of the tip of the tongue, (2) the side of the tongue ( $3 \mathrm{~cm}$ posterior to the tip), (3) the posterior tongue below the soft palate on the midline in the region of the circumvallate papillae, (4) the inside of the lower lip in front of the incisors, (5) the inside of the cheek opposite the molars, (6) the posterior (soft) palate approximately $1 \mathrm{~cm}$ behind the hard palate on the midline, and (7) the midline of the hard palate medial to the canine teeth. Subjects participated in four sessions, two for each irritant compound. Half the subjects received capsaicin first, and half received piperine first. Either three or four loci were stimulated in each session, in a randomly determined sequence.

Before each test, the subject rinsed with distilled water and expectorated. Then the experimenter, using forceps, placed a stimu- lus paper on a site. The mouth was then closed, and the tongue was kept away from treated surfaces (if a tongue site was being stimulated, the tongue was kept away from all surfaces). Every $30 \mathrm{sec}$ for $5 \mathrm{~min}$, the subjects were given response sheets on which they (1) recorded their magnitude estimates of the intensity of irritation and (2) indicated on checklists the most appropriate descriptor from each of four general categories: taste, thermal, tactile, and flavor. Taste choices were sweet, sour, salty, bitter, and metallic. Thermal choices were burning, very hot, hot, very warm, and warm. Tactile choices were biting, pricking, piercing, itching, and stinging. Flavor choices were peppery, spicy, tangy, astringent, and flavorful. We chose the descriptors on the basis of previous work (Lawless, 1984). Responses of other or no sensation were also permitted. The subjects were not provided with definitions of the descriptors.

At the end of each test, the subject expectorated into a 30-ml cup, clearing the mouth of saliva. Whole-mouth clearing has been found to be as reliable as other salivary measurement procedures (Navazesh \& Christensen, 1982). Cups were weighed to the nearest $.01 \mathrm{~g}$. A minimum intertrial interval of 5 min was imposed between tests within sessions. A test was never begun if the subject reported residual sensations from the previous test. During the intertrial intervals, questionnaires were administered to the subjects to assess personality variables and preference for and frequency of eating hot and spicy foods. These data are not reported here.

Data were normalized to set the initial perceived intensity estimate for capsaicin at the tip of the tongue to 100 for each subject.

\section{RESULTS}

The mean perceived intensities of irritation are shown for the seven loci over time in Figure 1 (capsaicin) and Figure 2 (piperine). For both compounds, irritation increased over time $[F(9,171)=17.14, p<.01]$ and was described by an exponential approach to an asymptote in the equation

$$
R=R_{\max }-e^{-t t},
$$

where $R_{\max }$ is the asymptote and $\mathrm{k}$ is a rate constant (Riggs, 1963). Table 1 gives these constants for each curve, fitted by an iterative procedure from RS-1 (BBN Research Systems, 1983) ( $r^{2}$ s exceeded .9).

Table 1

Parameter Estimates for Capsaicin and Piperine

\begin{tabular}{lrrrr}
\hline \multirow{1}{*}{ Locus } & \multicolumn{2}{c}{$R_{\max }$} & & \multicolumn{2}{c}{$k$ Rate Constant } \\
\cline { 2 - 5 } & $M$ & $S E M$ & & \multicolumn{1}{c}{ Capsaicin } \\
Tip of tongue & 342 & 11 & .53 & .04 \\
Lip & 266 & 7 & .59 & .04 \\
Side of tongue & 214 & 6 & .57 & .05 \\
Posterior palate & 212 & 5 & .50 & .03 \\
Back of tongue & 149 & 4 & .45 & .03 \\
Anterior palate & 125 & 17 & .37 & .10 \\
Cheek & 86 & 2 & .68 & .06 \\
& & Piperine & & \\
Tip of tongue & 278 & 8 & .60 & .05 \\
Lip & 127 & 8 & .43 & .06 \\
Side of tongue & 156 & 8 & .60 & .09 \\
Posterior palate & 165 & 12 & .42 & .06 \\
Back of tongue & 60 & 2 & .79 & .10 \\
Anterior palate & 40 & 2 & 1.28 & .29 \\
Cheek & 60 & 2 & .83 & .08 \\
\hline
\end{tabular}


Table 2

Saliva Flow (in Grams)

\begin{tabular}{lcccc}
\hline & \multicolumn{2}{c}{ Capsaicin } & \multicolumn{2}{c}{ Piperine } \\
\cline { 2 - 5 } \multicolumn{1}{c}{ Locus } & $M$ & $S E M$ & $M$ & SEM \\
\hline Tip of tongue & 7.9 & 1.3 & 5.1 & 0.6 \\
Lip & 2.3 & 0.3 & 2.2 & 0.2 \\
Side of tongue & 3.8 & 0.7 & 3.2 & 0.5 \\
Posterior palate & 3.2 & 0.4 & 2.2 & 0.2 \\
Back of tongue & 3.0 & 0.4 & 1.9 & 0.2 \\
Anterior palate & 2.6 & 0.4 & 1.6 & 0.2 \\
Cheek & 2.3 & 0.4 & 1.9 & 0.3 \\
\hline
\end{tabular}

Note-Values are means for whole-mouth flow over $5 \mathrm{~min}$.

Differences in responsiveness were observed among loci $[F(6,114)=15.08, p<.01]$. For both compounds, the tip of the tongue was the most responsive area. The remaining areas fell roughly into two groups: a moderately responsive group-the lip, posterior palate, and side of the tongue; and a group of areas with low responsesthe anterior palate, back of the tongue, and cheek.

This pattern was not the same for the two compounds, however. One major difference was that the lip was highly responsive to capsaicin (mean over time $=193$ ), but moderately responsive to piperine (mean over time $=81$ ) (orthogonal planned comparison [Hays, 1981], $p<.001$ ). A similar two-to-one difference was also seen between responses made to stimulation of the posterior tongue by capsaicin (mean $=97$ ) and by piperine (mean $=48 ; p<.05$ ).

Saliva weights are shown in Table 2. Stimulation of the tongue tip evoked the largest salivary response for both compounds. Capsaicin was a more potent stimulator of saliva than was piperine in all cases except for stimulation of the lip [stimulus $\times$ locus interaction, $F(6,114)=$ $4.15, p<.01$; Duncan multiple range tests on individual loci, $p<.01$ in all cases but the lip].

The frequencies of choices of different descriptors for each locus are shown in Table 3 for capsaicin and Table 4 for piperine. No taste and no flavor were the most frequently chosen descriptors $(58 \%$ of the taste category and $59 \%$ of the flavor category, respectively). The two compounds were similar in the overall frequencies of descriptors chosen $(r=.94)$.

In spite of this similarity, a compound $\times$ locus $\times$ descriptor interaction was observed $[F(114,2166)=1.66$,

Table 3

Descriptor Totals-Capsaicin

\begin{tabular}{|c|c|c|c|c|c|c|c|}
\hline \multirow[b]{2}{*}{ Attribute } & \multicolumn{7}{|c|}{ Locus } \\
\hline & $\begin{array}{l}\text { Tip of } \\
\text { Tongue }\end{array}$ & Lip & Cheek & $\begin{array}{c}\text { Posterior } \\
\text { Palate }\end{array}$ & $\begin{array}{c}\text { Anterior } \\
\text { Palate }\end{array}$ & $\begin{array}{c}\text { Posterior } \\
\text { Tongue }\end{array}$ & $\begin{array}{l}\text { Side of } \\
\text { Tongue }\end{array}$ \\
\hline \multicolumn{8}{|l|}{$\overline{\text { Taste }}$} \\
\hline Sweet & 1 & 0 & 0 & 0 & 7 & 0 & 1 \\
\hline Sour & 3 & 3 & 15 & 0 & 5 & 0 & 9 \\
\hline Salty & 36 & 20 & 23 & 19 & 17 & 10 & 12 \\
\hline Bitter & 61 & 21 & 16 & 33 & 0 & 26 & 59 \\
\hline Metallic & 36 & 6 & 15 & 37 & 43 & 58 & 43 \\
\hline Other & 0 & 0 & 0 & 0 & 0 & 0 & 0 \\
\hline No taste & 63 & 150 & 131 & 111 & 128 & 106 & 76 \\
\hline \multicolumn{8}{|l|}{ Thermal } \\
\hline Burning & 97 & 59 & 8 & 67 & 14 & 24 & 49 \\
\hline Very hot & 47 & 39 & 16 & 33 & 14 & 10 & 35 \\
\hline Hot & 36 & 31 & 27 & 30 & 9 & 15 & 45 \\
\hline Very warm & 16 & 36 & 35 & 13 & 32 & 42 & 25 \\
\hline Warm & 4 & 24 & 67 & 40 & 74 & 66 & 42 \\
\hline Other & 0 & 0 & 0 & 0 & 0 & 0 & 0 \\
\hline No thermal & 0 & 11 & 47 & 17 & 57 & 43 & 4 \\
\hline \multicolumn{8}{|l|}{ Tactile } \\
\hline Stinging & 108 & 78 & 39 & 67 & 39 & 48 & 93 \\
\hline Pricking & 21 & 11 & 37 & 45 & 42 & 33 & 37 \\
\hline Biting & 17 & 18 & 19 & 12 & 6 & 23 & 20 \\
\hline Itching & 27 & 9 & 22 & 20 & 12 & 22 & 14 \\
\hline Piercing & 14 & 39 & 1 & 35 & 15 & 16 & 13 \\
\hline Other & 0 & 3 & 2 & 1 & 4 & 2 & 0 \\
\hline No tactile & 13 & 42 & 80 & 20 & 82 & 56 & 23 \\
\hline \multicolumn{8}{|l|}{ Flavor } \\
\hline Peppery & 35 & 29 & 36 & 25 & 28 & 33 & 31 \\
\hline Spicy & 52 & 28 & 27 & 19 & 12 & 18 & 30 \\
\hline Tangy & 14 & 1 & 5 & 34 & 0 & 15 & 11 \\
\hline Astringent & 16 & 0 & 7 & 3 & 2 & 7 & 22 \\
\hline Flavorful & 0 & 0 & 0 & 0 & 10 & 0 & 7 \\
\hline Other & 0 & 0 & 0 & 0 & 0 & 8 & 0 \\
\hline No flavor & 83 & 142 & 125 & 119 & 148 & 129 & 99 \\
\hline
\end{tabular}


Table 4

Descriptor Totals-Piperine

\begin{tabular}{|c|c|c|c|c|c|c|c|}
\hline \multirow[b]{2}{*}{ Attribute } & \multicolumn{7}{|c|}{ Locus } \\
\hline & $\begin{array}{l}\text { Tip of } \\
\text { Tongue }\end{array}$ & Lip & Cheek & $\begin{array}{l}\text { Posterior } \\
\text { Palate }\end{array}$ & $\begin{array}{c}\text { Anterior } \\
\text { Palate }\end{array}$ & $\begin{array}{c}\text { Posterior } \\
\text { Tongue }\end{array}$ & $\begin{array}{l}\text { Side of } \\
\text { Tongue }\end{array}$ \\
\hline \multicolumn{8}{|l|}{ Taste } \\
\hline Sweet & 1 & 0 & 0 & 1 & 0 & 4 & 3 \\
\hline Sour & 0 & 3 & 4 & 0 & 10 & 2 & 5 \\
\hline Salty & 9 & 19 & 5 & 11 & 13 & 12 & 18 \\
\hline Bitter & 46 & 21 & 35 & 39 & 23 & 24 & 46 \\
\hline Metallic & 45 & 19 & 22 & 35 & 13 & 26 & 14 \\
\hline Other & 0 & 0 & 0 & 0 & 1 & 0 & 0 \\
\hline No taste & 99 & 138 & 134 & 114 & 140 & 132 & 114 \\
\hline \multicolumn{8}{|l|}{ Thermal } \\
\hline Burning & 64 & 15 & 12 & 21 & 5 & 3 & 21 \\
\hline Very hot & 53 & 14 & 5 & 21 & 2 & 9 & 21 \\
\hline Hot & 43 & 45 & 6 & 37 & 5 & 10 & 40 \\
\hline Very warm & 18 & 25 & 21 & 40 & 6 & 9 & 32 \\
\hline Warm & 17 & 68 & 60 & 61 & 74 & 118 & 77 \\
\hline Other & 0 & 0 & 3 & 0 & 3 & 0 & 0 \\
\hline No thermal & 5 & 33 & 93 & 20 & 105 & 51 & 9 \\
\hline \multicolumn{8}{|l|}{ Tactile } \\
\hline Stinging & 105 & 68 & 34 & 50 & 17 & 20 & 62 \\
\hline Pricking & 14 & 26 & 22 & 45 & 13 & 50 & 55 \\
\hline Biting & 11 & 3 & 4 & 12 & 3 & 9 & 10 \\
\hline Itching & 34 & 31 & 32 & 48 & 29 & 32 & 32 \\
\hline Piercing & 17 & 7 & 3 & 19 & 0 & 2 & 2 \\
\hline Other & 1 & 2 & 7 & 5 & 0 & 6 & 9 \\
\hline No tactile & 18 & 63 & 98 & 30 & 138 & 81 & 30 \\
\hline \multicolumn{8}{|l|}{ Flavor } \\
\hline Peppery & 63 & 39 & 32 & 40 & 20 & 34 & 40 \\
\hline Spicy & 42 & 34 & 34 & 27 & 7 & 17 & 48 \\
\hline Tangy & 10 & 17 & 9 & 19 & I & 10 & 11 \\
\hline Astringent & 0 & 0 & 0 & 9 & 0 & 6 & 11 \\
\hline Flavorful & 1 & 0 & 0 & 9 & 5 & 3 & 0 \\
\hline Other & 1 & 0 & 0 & 0 & 1 & 0 & 0 \\
\hline No flavor & 83 & 110 & 125 & 96 & 166 & 130 & 90 \\
\hline
\end{tabular}

$p<.01]$. Locus $\times$ descriptor and compound $\times$ descriptor interactions were also seen $[F(114,2166)=5.64$ and $F(19,361)=3.20$, respectively, $p s<.01]$. There was a complex pattern of descriptor choices for different loci and compounds. In the taste category, capsaicin evoked more metallic and fewer no taste choices. In the thermal category, capsaicin evoked more burning and very warm responses, whereas piperine evoked more warm and no thermal responses (see Figure 3). In the tactile category, capsaicin evoked more stinging, biting, and piercing choices, whereas piperine evoked more itching and no tactile choices than did capsaicin (Figure 4).

A principal-components analysis of the totals from Tables 3 and 4 (excluding descriptors with less than $5 \%$ total frequency) yielded six factors that accounted for $90 \%$ of the variance. The first was a general intensity factor, which correlated with 10 of the descriptors at $r \geq .5$ and accounted for $29 \%$ of the variance. The second was a burning pain factor which correlated with 8 descriptors (22\% of the variance). The third correlated with the bitter and metallic descriptors and negatively with no taste (14\%). The fourth factor correlated with tangy and pricking $(9 \%)$, the fifth with very warm and biting (9\%), and the sixth with salty $(8 \%)$.

\section{DISCUSSION}

Our results address the following issues: (1) the nature of spatial differences in oral responsiveness to irritants, (2) the possibility of qualitative differentiation of irritants, (3) patterns of temporal summation, and (4) the relationship of subjective intensity ratings to the magnitude of the evoked salivary reflex.

Two major findings concerned the spatial pattern of responsiveness. First, different oral loci are differentially responsive to oral chemical irritation. The present results showed the tip of the tongue to be most responsive; DunerEngstrom et al. (1986) also found the anterior tongue to be more responsive than the posterior. Green (1984) observed a similar pattern of responsiveness to thermal stimulation of the tongue and lip. He found the tongue tip to be more responsive than the tongue dorsum and the lip under most conditions.

The responsiveness of the tongue tip relative to other areas is predictable in light of anatomical and physiological observations. This area shows a higher density of fungiform papillae (Miller, 1986) than other areas of the tongue. The fungiform papillae, in addition to providing a supporting matrix for taste buds, are also richly inner- 


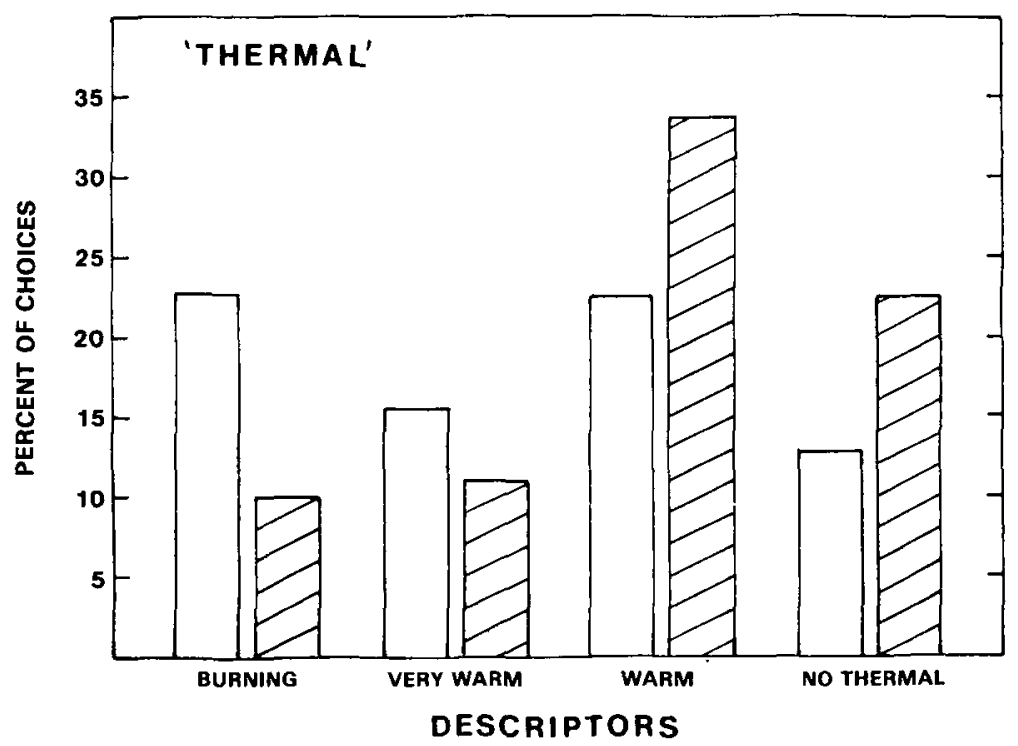

Figure 3. Mean frequency of choices (percent) allotted to selected thermal descriptors for capsaicin (open bars) and piperine (hatched bars).

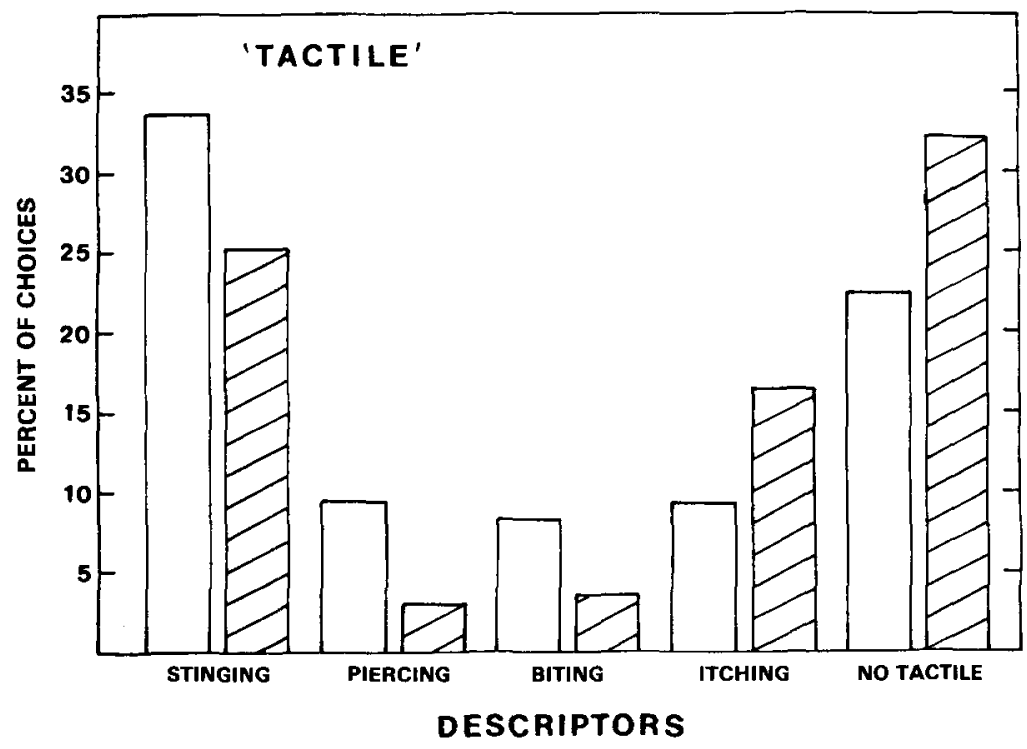

Figure 4. Mean frequency of choices (percent) allotted to selected tactile descriptors for capsaicin (open bars) and piperine (hatched bars).

vated by lingual trigeminal afferents (Beidler, 1969; Cheal \& Oakley, 1977; Farbman \& Hellekant, 1978; Miller, 1974; Whitehead, Beeman, \& Kinsella, 1985). Many of these fibers terminate in extremely superficial layers of the extragemmal cells surrounding the taste buds, making them well suited to interaction with the oral chemical milieu (Whitehead et al., 1985). Furthermore, they often show substance $P$ immunoreactivity, suggesting a role in nociception (Nagy, Goedert, Hunt, \& Bond, 1982; Nishimoto et al., 1982). The substance P-containing fibers of the glossopharyngeal nerve (Yamasaki, Kubota,
\& Tohyama, 1985) innervating the posterior tongue may be less responsive than the anterior trigeminal fibers, or, alternatively, there may be more restricted access of irritant molecules to receptors on the posterior tongue.

Our second important finding was that the two oral irritants were different in the spatial patterns of response they evoked. Capsaicin stimulated a greater response from the lip and posterior tongue than did piperine. These results are similar to previous observations based on frequencies of reports of irritation of areas following wholemouth stimulation (Lawless, 1984). There are also some 
similarities in the patterns of stimulation by the two irritants, with several oral areas being effectively stimulated by both compounds.

Differences in the spatial pattern of response to various irritant compounds provide an additional mechanism by which irritants might differ in perceived quality (as opposed to intensity). Consumers of hot and spicy foods often claim that different types of pepper burn different areas of the mouth. The locus $x$ compound $\times$ descriptor interaction noted in our descriptor frequency counts suggests differences in perceived quality in addition to variations in spatial pattern. Previous results provide indirect evidence for the possibility of qualitative differentiation. First, the course of decay of sensation over time differs for capsaicin and piperine (Stevens \& Lawless, 1986). Second, capsaicin's and piperine's patterns of interaction with the four basic tastes are different (Lawless \& Stevens, 1984). Third, studies of sensory interactions with sequential stimulus presentation suggest at least partial specificity of receptors for these two compounds (Stevens \& Lawless, 1987).

It is possible that qualitative differences in the current data may be explained in part by intensity differences and that higher concentrations of piperine may attenuate the differences we observed. However, complete equation of intensity is problematic. Due to the differences in growth of sensation with locus, concentration, and time, intensity equivalence could be achieved only at specific loci and specific time intervals. Qualitative differences may also be explained by side-bands, that is, sensations other than the burning pain and irritation characteristic of these stimuli. Although no taste and no flavor were the most frequently chosen descriptors, they were not universal. In particular, we were surprised to find salty chosen $8 \%$ of the time. This suggests that these compounds provide some minor but perceivable sensations in the classical gustatory qualities, and that these sensations may contribute to qualitative differences.

One unexpected result was that the perceived intensity of irritation grew over time and appeared to approach an asymptote; it did not decay within the time period we examined. This is in contrast to the decay in sensation that begins within about $1 \mathrm{~min}$ in whole-mouth "sip-and-spit" methods of stimulation (Lawless, 1984; Stevens \& Lawless, 1986). It could be argued that the growth in sensation is due to spreading of the stimulus, perhaps through salivary wetting. In other words, what appears to be a case of temporal summation could instead be a case of spatial summation. We find this suggestion questionable for several reasons. First, one other study in which small localized areas were stimulated showed growth of intensity over time; in that study, a flow chamber was used to stimulate the tongue surface (Lawless \& Gillette, 1985). With a flow chamber in contact with the extended tongue, salivary spreading can be ruled out. Second, the loci we studied were chosen (after extensive pilot work) to avoid areas in which salivary pooling would occur. Third, if salivary spread were a factor, one might expect reports of throat burn, which did not occur. Fourth, if salivary spread were a factor, there should have been greater perceived intensity in the "wetter" areas. Instead, we found that capsaicin produced a higher intensity estimate on the lip (a relatively dry spot) than on the side of the tongue (relatively more prone to wetting).

"Subjective" estimation of perceived intensities of irritation was largely paralleled by the "objective" measure of evoked salivary flow, as observed in other studies (Duner-Engstrom et al., 1986; Lawless, 1984). However, our results uncovered one important exception to this general relationship: although capsaicin was significantly higher in perceived intensity on the lip, stimulation of the lip evoked equivalent salivary flow for the two compounds. Therefore, proportionality of the magnitude of the salivary reflex response and the magnitude of sensation intensity should not be universally assumed.

\section{REFERENCES}

BBN Research Systems. (1983). RS-1 [Computer program]. Cambridge, MA: Author.

BeIDLER, L. M. (1969). Innervation of rat fungiform papilla. In C. Pfaffman (Ed.), Olfaction and taste III, (pp. 352-369). New York: Rockefeller University Press.

Cheal, M., \& OAKLey, B. (1977). Regeneration of fungiform taste buds: Temporal and spatial characteristics. Journal of Comparative Neurology, 172, 609-626.

Collings, V. B. (1974). Human taste response as a function of locus of stimulation on the tongue and soft palate. Perception \& Psychophysics, 16, 169-174.

Duner-Engstrom, M., Fredholm, B. B., Larsson, O., LundberG, J. M., \& SARIA, A. (1986). Autonomic mechanisms underlying capsaicin induced oral sensations in man. Journal of Physiology, 373, 87-96.

Farbman, A. I., \& Hellekant, G. (1978). Quantitative analyses of fiber populations in rat chorda tympani nerves and fungiform papillae. American Journal of Anatomy, 153, 509-521.

GelDard, F. A. (1972). The human senses (2nd ed.). New York: Wiley. Green, B. G. (1984). Thermal perception on lingual and labial skin Perception \& Psychophysics, 36, 209-220.

Hays, W. L. (1981). Statistics (3rd ed.). New York: Holt, Rinehart \& Winston.

Kenshalo, D. R. (1960). Comparison of thermal sensitivity of the forehead, lip, conjunctiva and cornea. Journal of Applied Physiology, 15, 987-991.

Kenshalo, D. R., Decker, T., \& Hamilton, A. (1967). Comparison of spatial summation on the forehead, forearm and back produced by radiant and conducted heat. Journal of Comparative \& Physiological Psychology, 63, 510-515.

LAWless, H. (1984). Oral chemical irritation: Psychophysical properties. Chemical Senses, 9, 143-155.

Lawless, H. T., \& Gillette, M. (1985). Sensory responses to oral chemical heat. In D. D. Bills \& C. J. Mussinian (Eds.), Recent advances in the characterization and measurement of flavor compounds (ACS Symposium Series 289). Washington, DC: American Chemical Society.

Lawless, H. T., \& Stevens, D. A. (1984). Effects of oral chemical irritation on taste. Physiology \& Behavior, 32, 995-998.

MiLler, I. J. (1974). Branched chorda tympani neurons and interactions among taste receptors. Journal of Comparative Neurology, 158, 155-166.

MiLler, I. J. (1986, July). Human fungiform taste bud density and distribution. Paper presented at the International Symposium on Olfaction and Taste and Association for Chemoreception Sciences, Snowmass, $\mathrm{CO}$.

Nagy, J. I., Goedert, M., Hunt, S. P., \& Bond, A. (1982). The nature of the substance $\mathrm{P}$-containing nerve fibers in taste papillae of the rat tongue. Neuroscience, 7, 3137-3151. 
Navazesh, M., \& Christensen, C. M. (1982). A comparison of whole mouth resting and stimulated salivary measurement procedures. Journal of Dental Research, 61, 1158-1162.

Nishimoto, T., Akai, M., Inagaki, S., Shiosaka, S., Shimizu, Y. Yamamoto, K., Senba, E., Sakanaka, M., Takatsuki, K., Hara, Y., Takagi, H., Matsuzaki, T., Kawai, Y., \& Tohyama, M. (1982). On the distribution and origins of substance $P$ in the papillae of the rat tongue: An experimental and immunohistochemical study. Journal of Comparative Neurology, 207, 85-92.

RIGGS, D. (1963). The mathematical approach to physiological problems. Baltimore: Williams \& Wilkins.

Sandick, B., \& Cardello, A. V. (1981). Taste profiles from single circumvallate papillae: Comparison with fungiform profiles. Chemical Senses, 6, 197-214.

Stevens, D. A., \& Lawless, H. T. (1986). Putting out the fire: Effects of tastants on oral chemical irritation. Perception \& Psychophysics, 39, 346-350.
Stevens, D. A., \& Lawless, H. T. (1987). Enhancement of responses to sequential presentation of oral chemical irritants. Physiology \& Behavior, 39, 63-65.

Stevens, J. C., Marks, L. E., \& Simonson, D. C. (1974). Regional sensitivity and spatial summation in the warmth sense. Physiology \& Behavior, 13, 825-836.

Whitehead, M. C., Beeman, C. S., \& Kinsella, B. A. (1985). Distribution of taste and general sensory nerve endings in fungiform papillae of the hamster. American Journal of Anatomy, 173, 185-201.

WILSKA, A. (1954). On the vibrational sensitivity in different regions of the body. Acta Physiologica Scandinavica, 31, 285-289.

Yamasaki, H., Kubota, Y., \& TOHYama, M. (1985). Ontongeny of substance $\mathrm{P}$-containing fibers in the taste buds and surrounding epithelium. Developmental Brain Research, 18, 301-305.

(Manuscript received November 21, 1986; revision accepted for publication July 20, 1987.) 